\title{
Suggested methods for estimation of confined strength of heterogeneous (defected) rocks
}

\author{
N Bahrani Dalhousie University, Canada \\ PK Kaiser Laurentian University, Canada \\ A Corkum Dalhousie University, Canada
}

\begin{abstract}
A grain-based model based on the distinct element method previously calibrated to the laboratory properties of intact and heat-treated (granulated) marble is used to simulate grain-scale heterogeneities, such as grain boundary cracks and laboratory specimen-scale heterogeneities (often referred to as defects), such as veins. The semi-empirical Strength Degradation Approach (SDA), originally developed for the estimation of the confined strength of crack-damaged rocks, is first applied and tested for the estimation of confined strength of laboratory specimen-scale rocks and rock blocks containing defects. In the second approach, called the explicit numerical modelling approach, the grain-based model is integrated with discrete fracture network (DFN) models, to construct defected rock models and to investigate the influence of defect orientation on the confined strength of defected rocks.

It is concluded that the SDA can be used at the early stages of geotechnical projects, when limited information on the properties and geometrical characteristics of defects is available. The explicit numerical modelling approach provides more representative results than the SDA, as it requires a detailed knowledge of the properties of intact rock as well as the properties and geometrical characteristics of defects obtained from field mapping and laboratory testing. A step-by-step procedure is provided for the application of these two methods to estimate the confined strength of defected rocks.
\end{abstract}

Keywords: heterogeneity, defects, rock block strength, Strength Degradation Approach (SDA)

\section{Introduction}

Heterogeneity plays a dominant role in the failure process and consequently affects the strength of rocks at different scales. Heterogeneities in rock include inter-grain and intra-grain cracks at the grain scale, small fractures, veins and cemented joints at the laboratory specimen and rock block scales, and block-forming joints at the rock mass scale. Other types of heterogeneities such as vesicles (cavities) and amygdaloids (filled cavities) can also influence rock failure process and strength. The presence of heterogeneities in rocks results in internal tensile stresses even in a moderate overall compressive stress field. These tensile stresses cause the initiation and propagation of tensile fractures before the peak stress is reached. It is known that heterogeneity reduces the unconfined compressive strength (UCS) of rocks. However, how the confined strength of a rock specimen is influenced by the presence of heterogeneities is less understood.

In cave mining operations, pillars experience complex loading and unloading cycles. These pillars are designed to provide confinement to the pillar core, ensuring their stability at different stages of the mining cycle. In recent years, deep caves with undercut levels at depths exceeding $1.5 \mathrm{~km}$ are being developed, and relatively wide pillars are required to maintain stability. At such depths, the magnitude of the confining stress in the core of wide pillars can exceed the confining pressures typically applied to rock specimens in laboratory triaxial tests. Hence, an accurate method to estimate the confined strength of rock masses is required to arrive at economic designs of pillars at great depths. This requires a reliable estimation of the confined strengths of heterogeneous rocks at the scales of laboratory specimen and intact rock blocks within the jointed rock mass. 
The focus of this paper is the confined strength estimation of rocks with heterogeneities at the laboratory specimen-scale and rock block-scale. Note that in this paper, grain-scale heterogeneities are referred to as cracks, and laboratory specimen and rock block-scale heterogeneities are referred to as defects. Two approaches are followed:

1. The Strength Degradation Approach (SDA): This approach was originally developed for the estimation of the confined strength of crack-damaged rocks (Bahrani \& Kaiser 2017). The applicability of this approach for the estimation of confined strength of defected rocks will be demonstrated in the published laboratory test data from mechanically slotted marble and large-scale coal specimens.

2. Explicit numerical modelling approach: This approach is based on explicit simulations of rock specimens containing defects. For this purpose, a calibrated grain-based distinct element model is integrated with discrete fracture networks (DFN) to construct defected rock models and investigate the influence of defects on the strength and failure modes of rocks as a function of confinement.

\section{Empirical methods for estimation of rock mass strength}

Empirical rock mass classification and characterisation systems are used at different stages of mining projects to provide information on the composition and characteristics of jointed rock masses. These systems provide initial estimates of support requirements for excavations (classification systems) and estimates of the anticipated strength and deformation properties of the rock mass (characterisation systems). Such empirical information is particularly useful during the early stages of any geotechnical project, when direct access to the rock mass and observations of rock mass behaviour are not possible. The most widely used methods for estimating the rock mass strength are the rock mass classification systems $Q$, Rock Mass Rating (RMR) and Mining Rock Mass Rating (MRMR), and the rock mass characterisation system Geological Strength Index (GSI).

Laubscher (1975) introduced the MRMR system to adjust the in situ RMR to fit the mining environment. Practical applications of the MRMR system as summarised by Laubscher (1990) include support design, determination of cavability, stability of open stopes, pillar design, extent of caves and failure zones, caving fragmentation, mining sequence, potential for massive wedge failure and design of pit slopes. Among available empirical approaches, MRMR provides the most systematic approach to estimate the unconfined compressive strength of the jointed rock mass from that of intact rock, as it considers the influence of heterogeneities at various scales (Figure 1(a)). Laubscher and Jakubec (2000) describe a procedure to determine the intact rock strength (IRS) from the results of UCS tests on rock cores by considering small-scale heterogeneities, the rock block strength (RBS) by considering scale effect and specimen-scale heterogeneities, and the rock mass strength (RMS) by considering the influence of large-scale heterogeneities (i.e. open joints and faults).

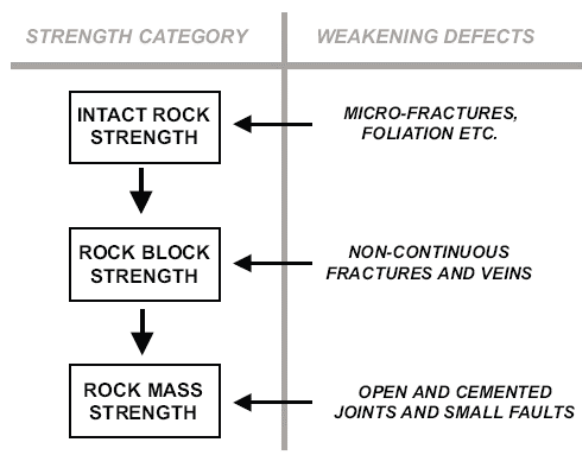

(a)

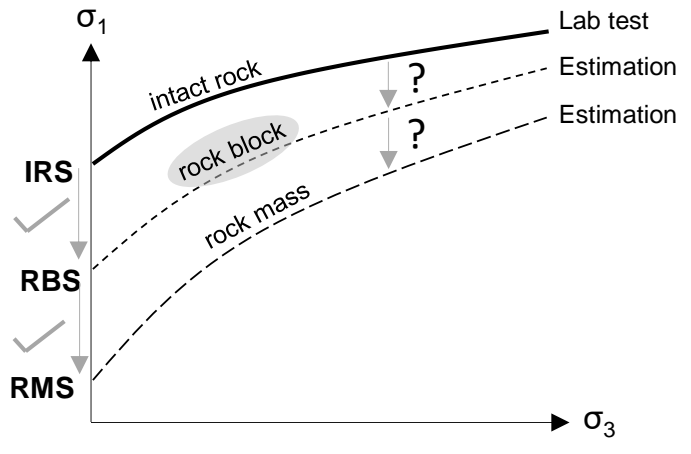

(b)

Figure 1 (a) Strength category and potential weakening heterogeneities (defects) in the MRMR system (Laubscher \& Jakubec 2000); and, (b) Strength degradation from intact rock to rock block due to rock block-scale heterogeneities, and from rock block to rock mass due to rock mass-scale heterogeneities as a function of confinement 
The unconfined compressive strength of jointed rock mass is an important parameter for the design of underground excavations, especially when dealing with rocks near the excavation boundaries, where the confinement is relatively low. A knowledge of the strength of jointed rock masses at high confinement becomes relevant when designing wide pillars or abutments at great depths, and when using continuum numerical approaches for simulating mine-scale problems, where the failure envelope of the jointed rock mass for a wide range of confinement is required. The GSI characterisation system provides an approach to estimate the failure envelope of a jointed rock mass from that of intact rock. However, as discussed by Bahrani and Kaiser (2013), the GSI-based equations for the estimation of RMS were developed based on the experience and observations of near-excavation behaviour in weak rock masses, and therefore, their application for strength estimation and design of highly confined rock masses in hard brittle rocks may not be valid. Moreover, the GSI approach does not consider the influence of block-scale heterogeneities on the strength of jointed rock masses. In some cases, this limitation may result in overestimated RMS. Therefore, as demonstrated in Figure 1(b), a practical methodology to estimate the confined strength of jointed rock masses should consider the confinement-dependent strength degradation of rock blocks from laboratory rock specimens due to the presence of rock block-scale heterogeneities, and then the confinement-dependent strength degradation of jointed rock mass from rock blocks due to the presence of rock mass-scale heterogeneities. The focus of this paper is on the estimation of the confined strength of laboratory rock specimens and rock blocks due to the presence of heterogeneities, called defects.

\section{Numerical simulation of heterogeneous rocks}

The laboratory program carried out by Rosengren and Jaeger (1968) and Gerrogiannopoulos (1976) on Wombeyan marble provides an analogy for crack-damaged rocks. A numerical study, based on the results of laboratory tests on Wombeyan marble, was conducted to investigate the mechanisms involved in the confinement-dependent strength degradation of crack-damaged rocks from intact rocks (Bahrani et al. 2014). The calibrated numerical models were extended to investigate the influence of specimen size on the unconfined compressive strength of defected rocks (Bahrani \& Kaiser 2016b, c). In addition, a semi-empirical approach, based on the results of numerical simulations, was developed to estimate the confined strength of crack-damaged rocks (Bahrani \& Kaiser 2017, 2016a). This section provides an overview of the numerical simulations of Wombeyan marble using a grain-based distinct element modelling approach and its extensions to crack-damaged and defected rocks.

\subsection{Properties of intact and heat-treated Wombeyan marble}

Rosengren and Jaeger (1968) and Gerrogiannopoulos (1976) found that when a specimen of coarse-grained Wombeyan marble is heated to $\sim 600^{\circ} \mathrm{C}$, the anisotropy in thermal expansion of calcite grains causes complete separation of the grains at their boundaries. The heat-treated (granulated or crack-damaged) marble had a low direct tensile strength of $0.03 \mathrm{MPa}$, compared to $7 \mathrm{MPa}$ before the heat treatment. The heating process reduced the unconfined compressive strength of marble from $U \mathrm{USS}_{i}=70 \mathrm{MPa}$ (intact rock UCS) to about UCS I $_{d} 20 \mathrm{MPa}$ (granulated or crack-damaged rock UCS; see Figure 2). A small amount of confinement $\left(\sigma_{3} \leq U C S_{i} / 10\right)$ rapidly increased the granulated rock strength to about $80 \%$ of that of intact confined strength. At higher confinements, the strength drop from intact rock is constant at about 20 to $10 \%$ of UCS.

The equivalent friction angle ( $\phi_{\mathrm{e}}$ : basic friction plus dilation angle) in the low confinement range $\left(\sigma_{3}<U C S_{i} / 10\right)$ is $45^{\circ}$ and $55^{\circ}$ for the intact and granulated marble, respectively. The equivalent friction angles of both intact and granulated marble gradually decrease with increasing confinement and reach about $30^{\circ}$ for confining pressures greater than $10 \%$ of marble's intact unconfined compressive strength $\left(\sigma_{3}>U \mathrm{CS}_{\mathrm{i}} / 10\right)$. Beyond this critical confining pressure, dilation is inhibited, and the confined strength of granulated marble is lowered from the marble's intact strength by a constant amount of about $10 \mathrm{MPa}$. 


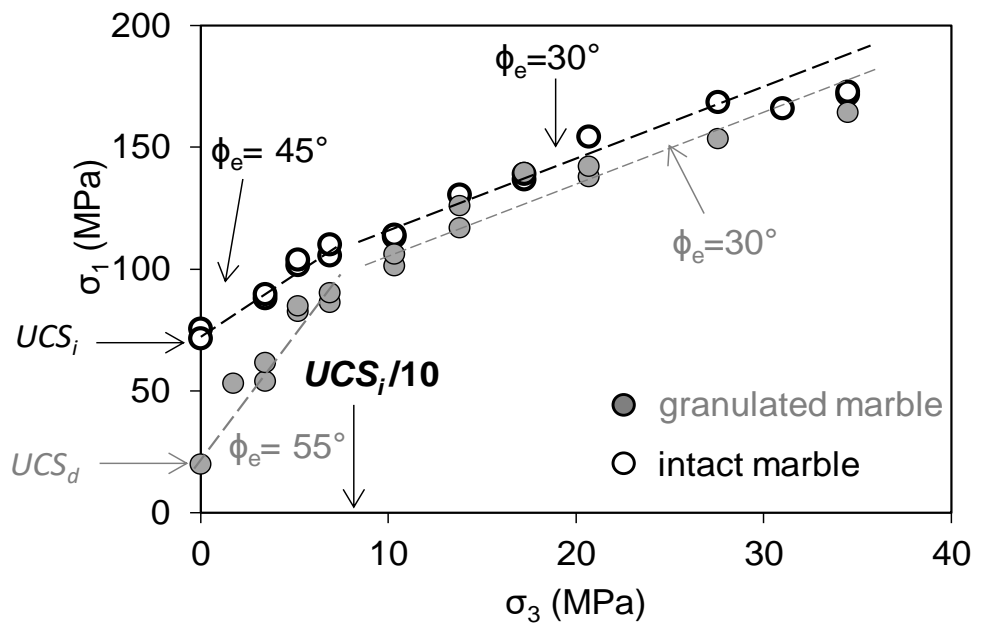

Figure 2 Unconfined and confined strengths of intact and granulated Wombeyan marble (after Gerogiannopoulos, 1976), and calculated equivalent friction angles for confinement ranges less than $10 \%$ of intact UCS $\left(\sigma_{3}<U C S_{i} / 10\right)$ and greater than $10 \%$ of intact UCS $\left(\sigma_{3}>U C S_{i} / 10\right)$

A grain-based distinct element model, where a rock is simulated with its deformable and breakable grains, is used to simulate the laboratory behaviour of intact and granulated Wombeyan marble presented in Figure 2 . This calibrated model is extended to simulate grain-scale and specimen-scale heterogeneities and investigate their influence on the confined strength of heterogeneous rocks.

\subsection{Simulation of intact and heat-treated marble}

Bahrani et al. (2014) used a numerical model based on the distinct element method to simulate the laboratory behaviour of intact and granulated Wombeyan marble reported by Gerogiannopoulos (1976) (Figure 3). This model was built using the two-dimensional Particle Flow Code (PFC) and its embedded grain-based model (GBM) developed by Potyondy (2010). In the GBM, a rock specimen is simulated with grains that are deformable and breakable. The internal grain material is simulated with a number of circular particles interacting through the software's parallel bond logic, and the grain boundaries are simulated using the smooth-joint contact logic. Figure 3(a) shows the GBM used to simulate Womebeyan marble, and Figure $3(\mathrm{~b})$ presents the calibration results, indicating excellent correspondence between the strengths of intact and granulated Wombeyan marble from laboratory tests and those obtained from the calibrated GBMs. The calibration procedure and details of the results are explained by Bahrani et al. (2014).

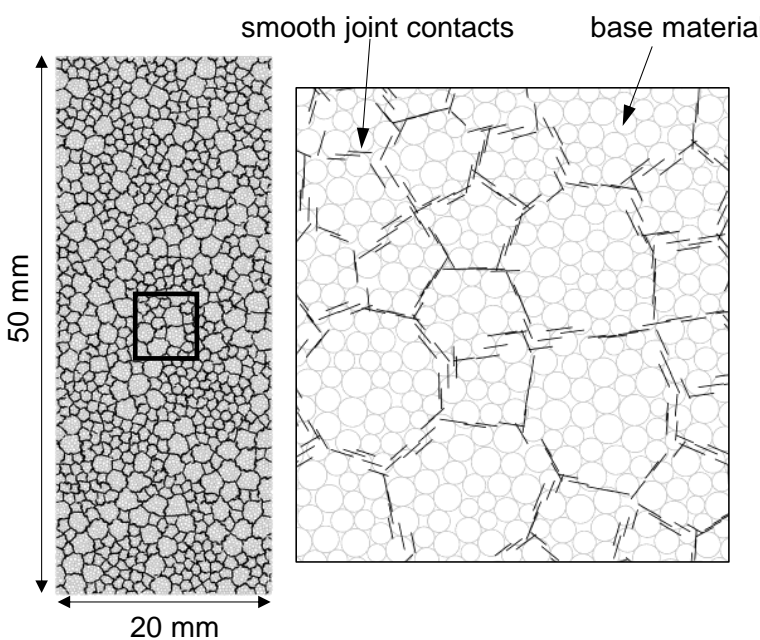

(a)

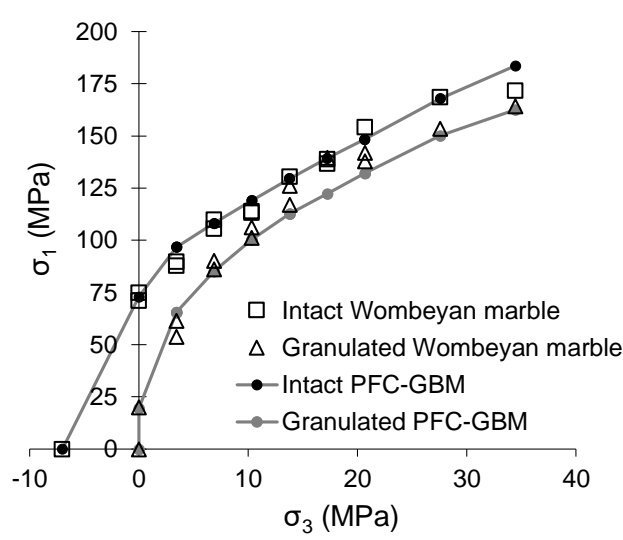

(b)

Figure 3 (a) Grain-based model of Wombeyan marble; and, (b) Correspondence between the strengths of laboratory and numerical specimens of intact and granulated marble (Bahrani et al. 2014) 


\subsection{Simulation of grain-scale heterogeneities (grain boundary cracks)}

The calibration of the GBMs was based on the assumption that heating intact marble affected the mechanical properties of the grain boundaries but not the grains (Bahrani et al. 2014). Hence, the smooth-joint contacts, representing the grain boundaries, were simulated as cohesive contacts in the model of intact marble, and as frictional (cohesionless) contacts in the model of granulated marble. In nature, a rock may consist of a combination of cohesive and frictional grain boundaries. Bahrani and Kaiser (2016a, 2017) used the calibrated GBMs and simulated crack-damaged specimens by assigning properties of frictional grain boundaries to a limited number of smooth-joint contacts (in increments of $10 \%$, from 0 to $90 \%$ of all smooth-joint contacts). A damage parameter $S J_{d}$ was introduced to describe the percentage of frictional smooth-joint contacts in a GBM. For example, Figure 4(a) shows a crack-damaged grain-based specimen, where the properties of the frictional smooth-joint contact were assigned to $50 \%$ of all the smooth-joint contacts (i.e. $S J_{d}=50 \%$ ). The cohesive smooth-joint contacts, shown with green lines in this figure, become frictional after they fail in tension or shear. Figure 4(b) shows the unconfined and confined strengths of the grain-based specimens with the percentage of frictional smooth-joint contacts ranging from $0 \%$ (i.e. model of intact marble) to $100 \%$ (i.e. model of granulated marble). This model reproduces the higher strength loss at low confinement $\left(\sigma_{3} \leq U C S_{i} / 10\right)$ with increasing frictional grain boundaries (i.e. frictional smooth-joint contacts), as observed for the Wombeyan marble presented in Figure 2.

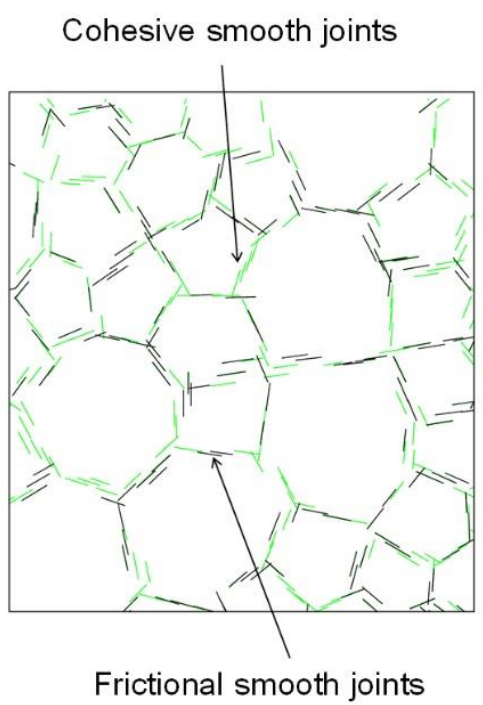

(a)

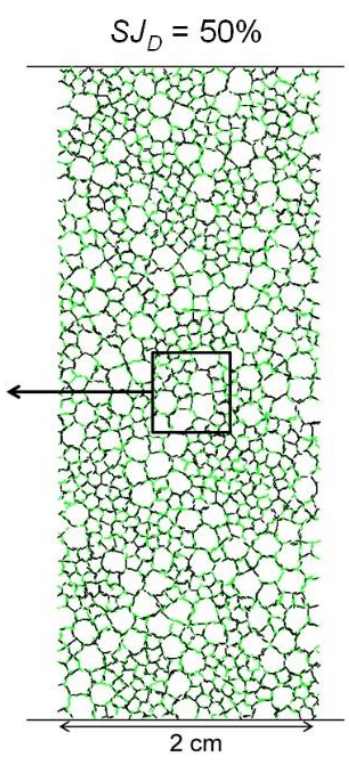

$2 \mathrm{~cm}$

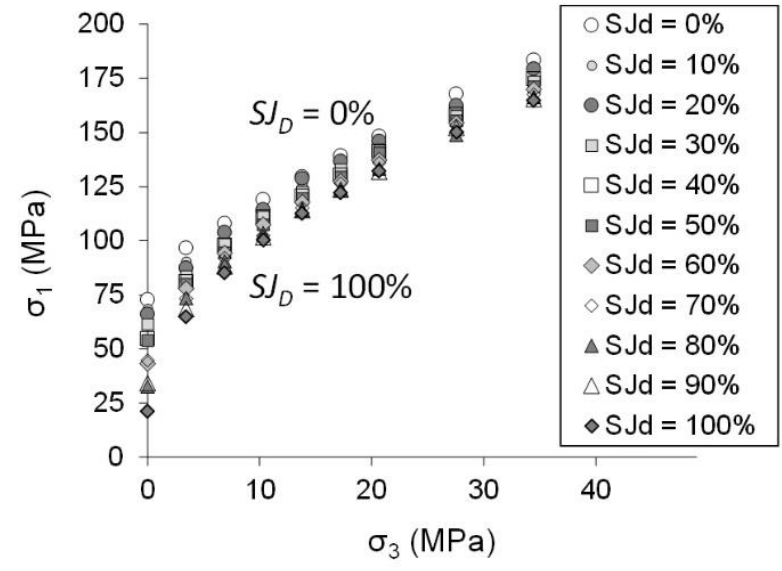

(b)

Figure 4 (a) A crack-damaged grain-based specimen, where $50 \%$ of the smooth-joint contacts are frictional $\left(S J_{d}=50 \%\right)$. Green and black smooth-joint contacts refer to cohesive and frictional grain boundaries; and, b) Strength of grain-based specimens with frictional smooth-joint contact densities ranging from $S J_{d}=0 \%$ to $100 \%$ (Bahrani \& Kaiser 2016a, 2017)

\subsection{Confined strength estimation of rocks containing grain-scale heterogeneities (crack-damaged rocks)}

Bahrani and Kaiser $(2016 a, 2017)$ developed a semi-empirical approach for the estimation of confined strength of rocks containing grain-scale heterogeneities (i.e. crack-damaged rocks) based on the results of numerical simulations of rock specimens with various levels of crack densities (Figure 4(b)). The semi-empirical approach, called the Strength Degradation Approach, describes the strength degradation of a crack-damaged rock from the intact rock as a function of confinement. Using this approach, having knowledge of the unconfined and confined strengths of the intact rock and the unconfined strength of the crack-damaged rock, the confined strength of the crack-damaged rock can be estimated. 
The general form of the strength degradation in the SDA takes the following form:

$$
D P_{d}=\left(D u_{d}-D c_{d}\right) e^{\left[100\left(-\sigma_{3} / \sigma_{c i}\right) / c_{d}\right]}+D c_{d}
$$

where $\mathrm{DP}_{d}$ is the degradation parameter which relates the strength degradation to confinement, $D u_{d}$ (unconfined degradation) is the value of $\mathrm{DP}_{d}$ at zero confinement, $\mathrm{Dc}_{\mathrm{d}}$ (confined degradation) is the value of $D P_{d}$ at high confinement, $c_{d}$ controls the curvature of the trend line, and $\sigma_{c i}$ is the uniaxial compressive strength of the intact rock obtained by back projecting the Hoek-Brown failure criterion fitted to the triaxial test data of intact rock to the unconfined state. The parameters $D u_{d}, D c_{d}$ and $c_{d}$ are obtained using the following equations:

$$
\begin{aligned}
D u_{d} & =\left[\left(\sigma_{c i}-U C S_{d}\right) / \sigma_{c i}\right] \times 100 \\
D c_{d} & =-17.3 e^{-0.017 D u_{d}}+17.3 \\
c_{d} & =10.8 e^{-0.055 D u_{d}}+4.5
\end{aligned}
$$

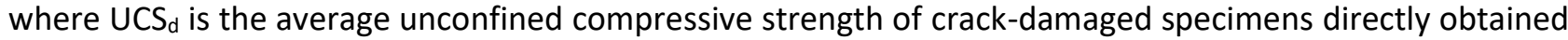
from laboratory unconfined compression tests. Once the strength degradation of crack-damaged rock specimens $\left(D P_{d}\right)$ is obtained as a function of confinement, the confined strength of such specimens can be estimated using the following equation:

$$
\sigma_{1 d}=\sigma_{1 i} \times\left[1-\left(D P_{d} / 100\right)\right]
$$

The following steps can be taken to estimate the confined strength of crack-damaged rocks using the SDA:

Step 1: The Hoek-Brown (HB) failure envelope is fitted through the unconfined and confined strengths of intact rock obtained from laboratory testing. The HB failure envelope is used to determine the unconfined compressive strength of intact rock, $\sigma_{\mathrm{c} \text {, }}$ by fitting the criterion through the results of triaxial compression tests. Note that $\sigma_{\mathrm{ci}}$ and UCS ${ }_{i}$ are two different parameters (Kaiser \& Kim 2015).

Step 2: Equation 2 is used to determine the unconfined strength degradation, $D u_{d}$, from the unconfined compressive strength of intact rock $\left(\sigma_{\mathrm{ci}}\right)$ from Step 1, and the average unconfined compressive strength of crack-damaged rocks $\left(\mathrm{UCS}_{\mathrm{d}}\right)$ from laboratory testing.

Step 3: The values of the degradation parameter function, $D c_{d}$ and $c_{d}$, are determined from Equations 3 and 4, respectively.

Step 4: The degradation parameter $\mathrm{DP}_{\mathrm{d}}$ is determined using Equation 1.

Step 5: The degraded strength envelope for crack-damaged rocks is then estimated using Equation 5.

Bahrani and Kaiser (2017) investigated the applicability of the SDA in estimating the confined strength of crack-damaged rocks by comparing it with published laboratory tests. They concluded that the SDA provides a reliable estimate of the mean confined strength of rock specimens containing various degrees of grain-scale heterogeneity (i.e. crack densities). Figure 5 presents two examples of the application of the SDA for the estimation of confined strength of granulated Wombeyan marble (Rosengren \& Jaeger 1968) and stress-damaged Lac du Bonnet (LdB) granite (Martin 1993). This figure shows that the SDA captures the increase in the strengths of granulated Wombeyan (highly damaged) and LdB granite (moderately damaged) at low confinement. Considering the inherent variability in the strength data from even the most well-conducted laboratory programs, the SDA reasonably predicts the confined strength envelopes over a wide range of confinement. This is particularly evident in the case of granulated Wombeyan marble (Figure 5(a)). 


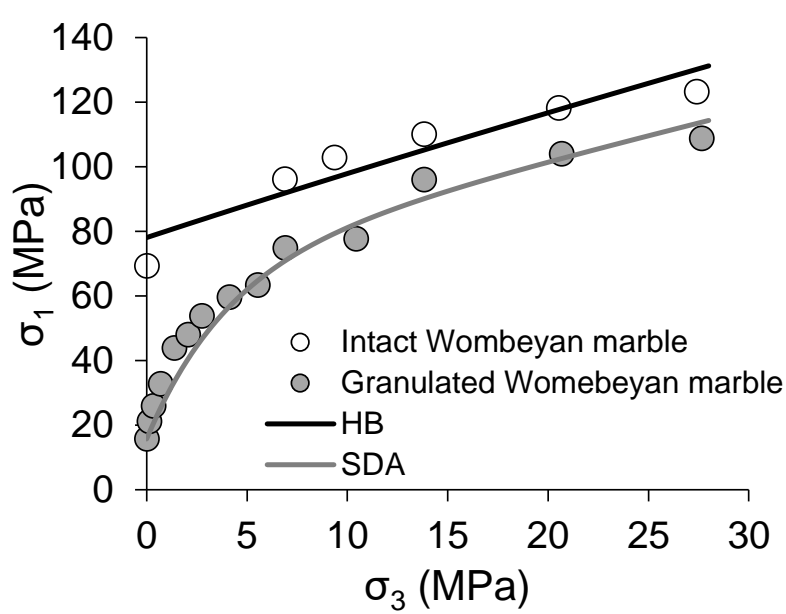

(a)

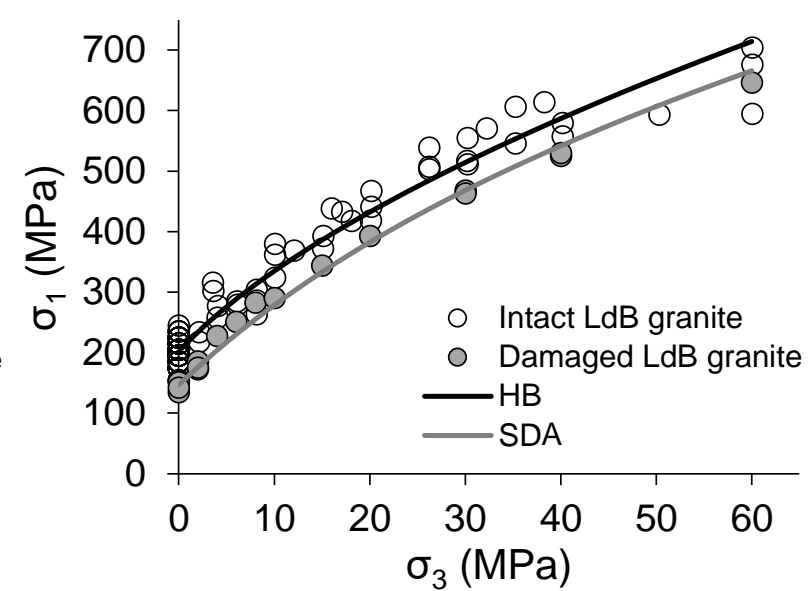

(b)

Figure 5 Laboratory data of (a) Intact and granulated Wombeyan marble (Rosengren \& Jaeger 1968); and, (b) Intact and damaged LdB granite (Martin 1993), and the strength envelopes of intact specimens obtained using the HB failure criterion (solid black curve), and those predicted for the crack-damaged specimens using the SDA (grey curve)

\subsection{Simulation of laboratory specimen-scale heterogeneities (defects)}

Bahrani and Kaiser $(2016 \mathrm{~b}, \mathrm{c}$ ) investigated the influence of specimen size on the unconfined compressive strength of rocks containing specimen-scale heterogeneities (defects) such as veins. They generated hypothetical DFN models to simulate defects. The generated DFN models consisted of two sets of defects with different orientations. In total, six $12 \times 24 \mathrm{~cm}$ DFN models with the defect configurations listed in Table 1 were generated. The geometries of DFN models are shown in Figure 6(a). Five samples were taken from the centres of each DFN model to generate five smaller DFN models with widths ranging from 1 to $5 \mathrm{~cm}$ and a height-to-width ratio of 2.5 (Figure 6(b)). Five grain-based specimens with widths of 1 to $5 \mathrm{~cm}$ with height-to-width ratios of 2.5 were also generated following the procedure described by Bahrani et al. (2014), with the micro-properties of intact grain-based specimen. The DFN models were overlaid on these grain-based models to generate GB-DFN models (Figure 6(c)). The defect structure was replaced by smooth-joint contacts of lower tensile strength, cohesion and friction angle compared to those of the grain boundaries (defect properties: peak $\phi_{j}=0^{\circ}, c_{j}=6.5 \mathrm{MPa}, \sigma_{t j}=1 \mathrm{MPa}$, residual $\phi_{j}=35^{\circ}, c_{j}=0 \mathrm{MPa}, \sigma_{t j}=0 \mathrm{MPa}$ ).

Table 1 Configuration of defects in DFN models

\begin{tabular}{llllllll}
\hline \multirow{2}{*}{ DFN \# } & \multirow{2}{*}{$\begin{array}{l}\text { Joint } \\
\text { set \# }\end{array}$} & \multicolumn{2}{l}{ Dip angle $\left(^{\circ}\right)$} & \multicolumn{2}{l}{ Length $(\mathbf{m m})$} & \multicolumn{2}{l}{ Persistence } \\
& Mean & Std dev. & Mean & Std dev. & Mean & Std dev. \\
\hline \multirow{2}{*}{ 1, 2 and 3 } & 1 & 0 & 5 & 20 & 5 & 0.5 & 0.1 \\
& 2 & 90 & 5 & 20 & 5 & 0.5 & 0.1 \\
\multirow{4}{*}{4 and 5 } & 1 & 40 & 5 & 20 & 5 & 0.5 & 0.1 \\
& 2 & 130 & 5 & 20 & 5 & 0.5 & 0.1 \\
6 & 1 & 20 & 5 & 20 & 5 & 0.5 & 0.1 \\
& 2 & 110 & 5 & 20 & 5 & 0.5 & 0.1 \\
\hline
\end{tabular}




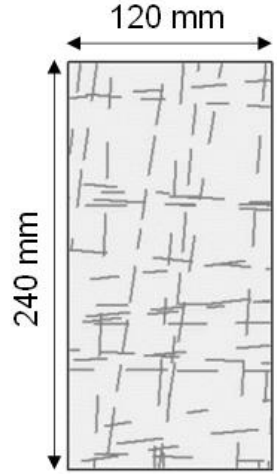

DFN1

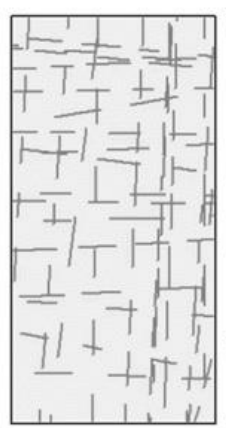

DFN2

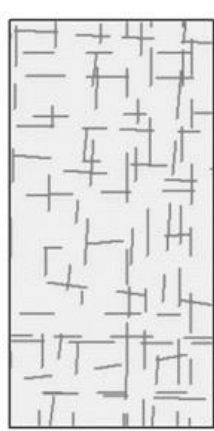

DFN3

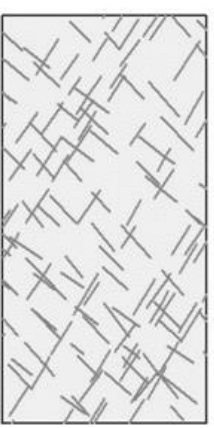

DFN4

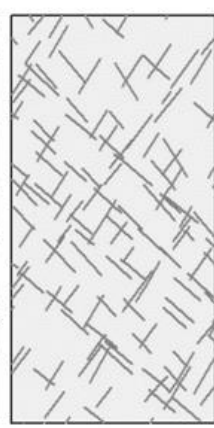

DFN5

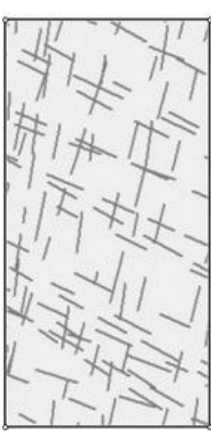

DFN6

(a)

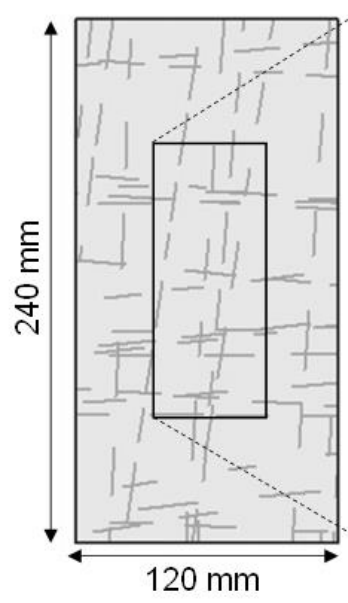

(b)

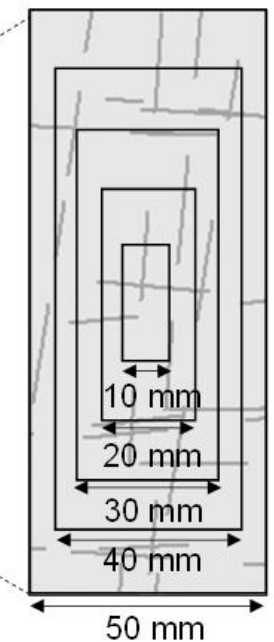

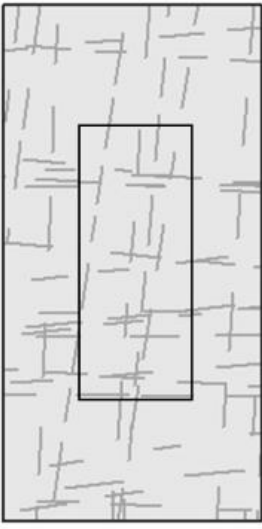

DFN

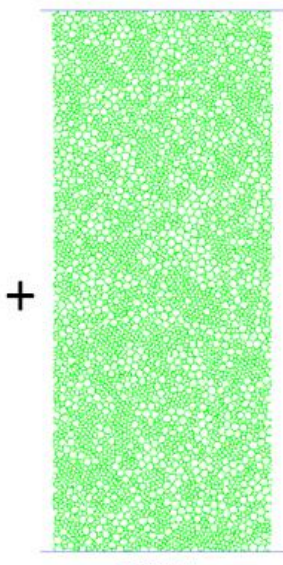

GBM

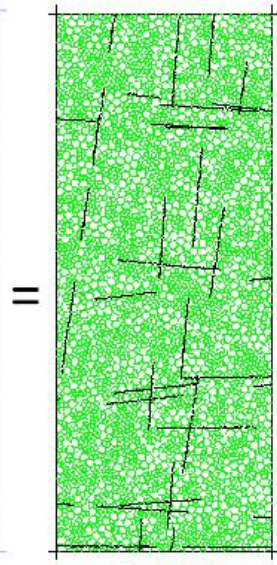

GB-DFN (c)

Figure 6 (a) Six hypothetical $12 \times 24 \mathrm{~cm}$ DFN models; (b) Five samples taken from the centre of the original DFN model; and, (c) Integration of the GBM and DFN models and the generation of the GB-DFN model (Bahrani \& Kaiser 2016b, c)

A series of UCS tests were simulated on the GB-DFN specimens of different sizes, and the results in terms of the peak strength were used to investigate the influence of specimen size on the unconfined compressive strength of defected rocks. Figure 7 presents the failure modes of differently sized GB-DFN1 specimens. This figure shows that the failure mode of the GB-DFN1 specimens containing defects with mean dip angles of 0 and $90^{\circ}$ is independent of the size of specimens. In all specimens, the interaction between inter-grain tensile cracks and the nearly vertical defects failed in shear results in the formation of macroscopic nearly axial fractures.

The results of scale effect test simulations on all the GB-DFN specimens are summarised in Figure 8 with plots of peak strength versus specimen width. It can be seen from this figure that the strength of an intact specimen with no defects is independent of specimen size, as is expected for tests conducted with frictionless platens. The specimen with defects oriented parallel and perpendicular to the loading direction (GB-DFN1, GB-DFN2 and GB-DFN3) show a small reduction in strength with the increase in specimen size. The specimens with critically oriented defects (GB-DFN4 and GB-DFN5) exhibit the lowest strengths independent of specimen size. The strength of GB-DFN6 changes rapidly with increasing specimen size and reaches about $40 \%$ of the intact strength for the largest specimen size. Note that the low strength of GB-DFN6 with a width of $10 \mathrm{~mm}$ is due to its failure along a single defect.

The $5 \times 12.5 \mathrm{~cm} \mathrm{GB-DFN1} \mathrm{and} \mathrm{GB-DFN4} \mathrm{specimens} \mathrm{are} \mathrm{used} \mathrm{in} \mathrm{Section} 3.2$ to investigate the influence of confinement and defect orientation on the strength degradation of defected rocks. 


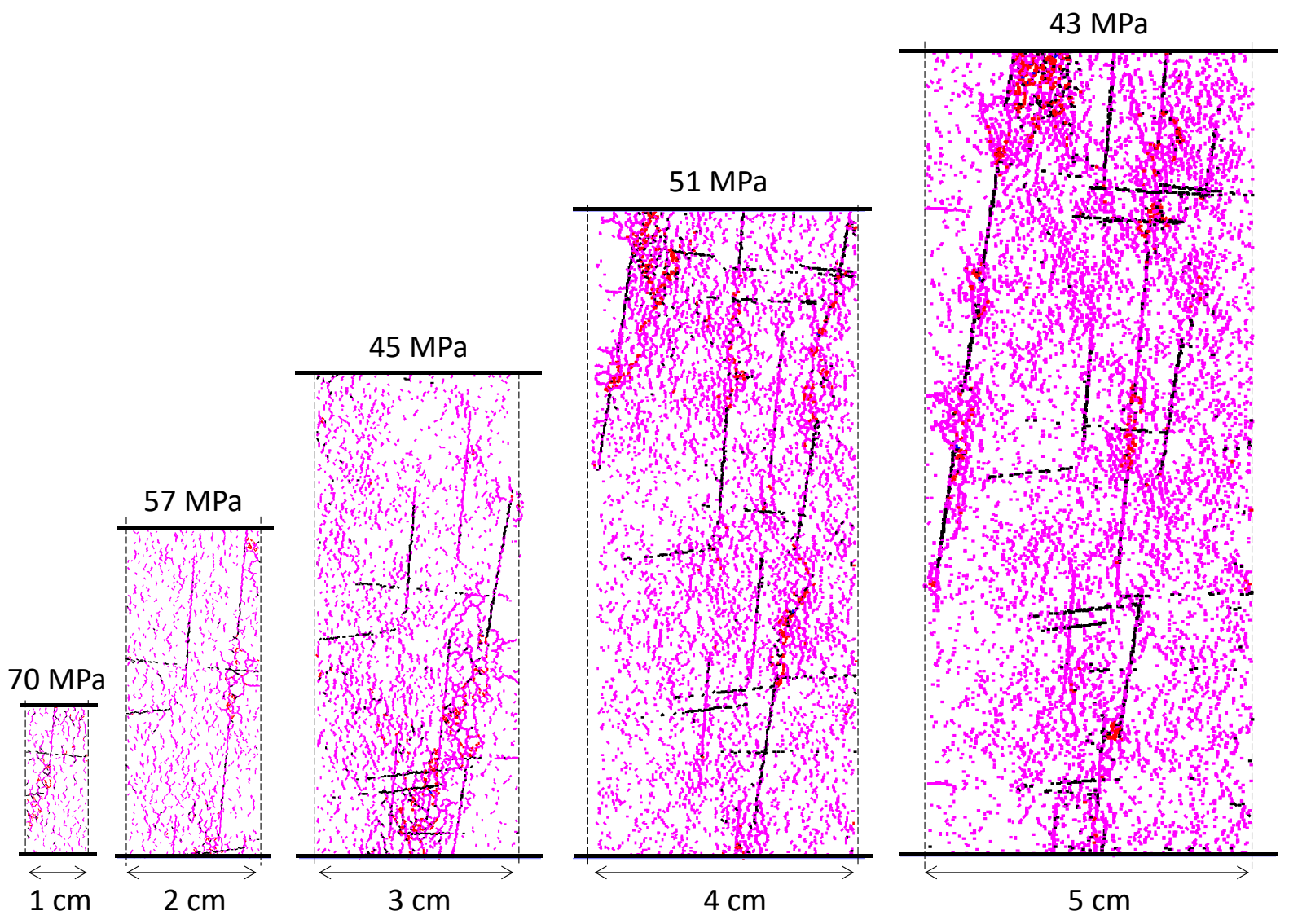

Figure 7 Failure modes and unconfined compressive strengths of GB-DFN1 specimens. Pink and black refer to smooth-joint contact tensile and shear cracks (inter-grain cracks or defects), respectively, and red and blue refer to parallel bond tensile and shear cracks (intra-grain cracks)

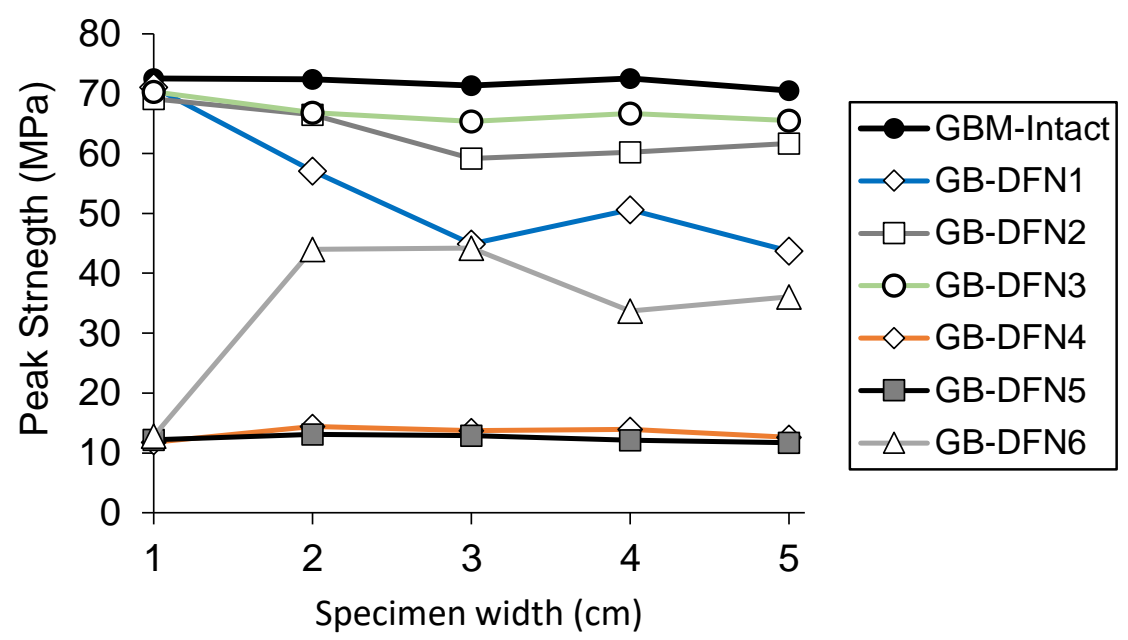

Figure 8 Results of numerical analysis on differently sized intact and defected grain-based specimens (Bahrani \& Kaiser 2016b, c) 


\section{$4 \quad$ Confined strength estimation of rocks containing laboratory specimen-scale heterogeneities (defected rocks)}

In this section, two methods to estimate the confined strength of defected rocks are presented. The first approach is based on the SDA reviewed in Section 2.4, while the second approach is based on explicit simulation of defected rocks, and therefore requires the knowledge of the properties of intact rock and the properties and geometrical characteristics of the defects obtained from laboratory testing and field mapping.

\subsection{Method 1: Strength Degradation Approach}

The SDA, originally developed to estimate the confined strength of crack-damaged rocks, is used in this section to investigate its applicability for the estimation of confined strength of rocks containing specimen-scale heterogeneities (i.e. defected rocks). For this purpose, the analyses were conducted on the laboratory tests on mechanically slotted marble representing a defected rock, and large-scale coal specimens containing cleats as defects.

Yang et al. (2008) investigated the mechanical properties of marble containing two discrete gypsum-filled machined slots. They used a high-speed electric cutting machine to cut planar flaws in the marble with different angles relative to the specimen axis. The slot thickness was about 0.3 to $0.5 \mathrm{~mm}$. The samples were divided into two types; intact marble with no slots, and slotted marble with slot orientations relative to the specimen axis, ranging from 30 to $60^{\circ}$. The specimens with slots filled with gypsum are considered as models of defected rocks. Under an unconfined condition, the slots were directly involved in the failure of the specimens and caused the specimens to fail at a lower strength. The fractures nucleated from the tips of these slots and propagated to the boundaries of the specimens or towards the tips of the other slot. Yang et al. (2008) indicated that both the intact and slotted specimens failed by shearing through the intact part of the specimens at high confinement, as also indicated by Jaeger and Cook (1976).

The results of laboratory tests on fine-grained and coarse-grained marble are shown in Figures $9(\mathrm{a})$ and (b), respectively. In the analysis using the SDA, it was assumed that the unconfined and confined strengths of intact marble, and the unconfined strength of slotted marble were known. Therefore, the SDA was used to estimate the confined strength of the slotted specimens. Figure 9 shows that the SDA captures the rapid increase in the strength of both coarse-grained (Figure 9(a)) and fine-grained (Figure 9(b)) slotted specimens at low confinement and reasonably estimates their strengths at high confinement.

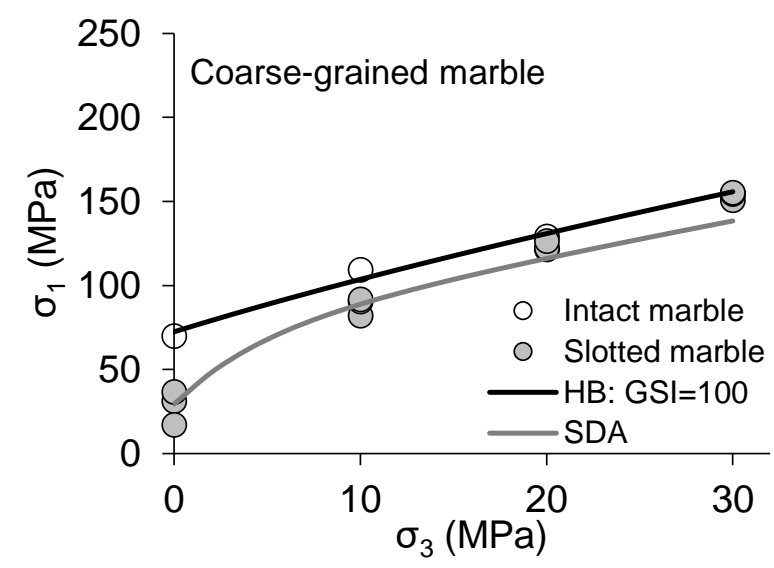

(a)

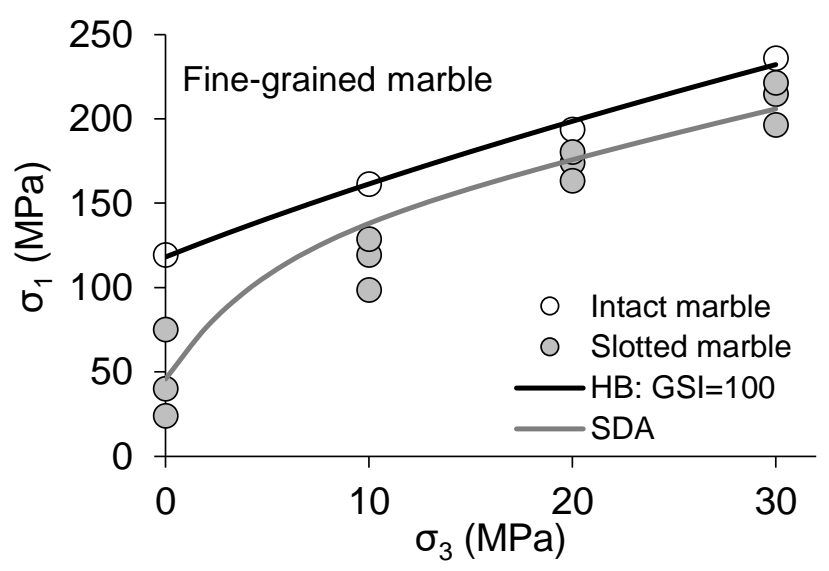

(b)

Figure 9 Laboratory data of intact and slotted (a) Coarse-grained; and, (b) Fine-grained marble, and the estimation of confined strengths of slotted marble using the SDA (data from Yang et al. 2008) 
It is known that the strength of a rock decreases with increased specimen size. However, how the confined strength of a rock is influenced by the specimen size is not well understood. A majority of laboratory tests on the influence of specimen size on rock strength were conducted under an unconfined condition. Few investigations have been reported on the influence of specimen size, and, therefore, the presence of specimen-scale heterogeneities on the confined strength of rock (e.g. Medhurst \& Brown 1998).

Further analysis was conducted in this section to investigate the applicability of the SDA for estimating the confined strength of rock blocks on the limited data from laboratory experiments on large-sized coal specimens by Medhurst and Brown (1998). They conducted triaxial tests on 61, 146 and 300 mm diameter coal specimens. Their experiments did not include UCS tests, and the applied confining pressure ranged from 0.2 to $10 \mathrm{MPa}$. Medhurst and Brown (1998) found that the failure mode changed from axial splitting at confining pressures of less than $1 \mathrm{MPa}$ to shear failure at confining pressures greater than $1 \mathrm{MPa}$ (i.e. at about $\left.\sigma_{3}=U C S / 15\right)$.

Figure 10 presents the results of the triaxial compression tests on 61 and $146 \mathrm{~mm}$ diameter coal specimens (Figure 10(a)), and 61 and $300 \mathrm{~mm}$ diameter coal specimens (Figure 10(b)). It is evident from the data presented in this figure that the rock strength decreases with increased specimen size. However, the amount of strength reduction depends on the confinement. The observed reduction in strength with increased specimen size was interpreted by Medhurst and Brown (1998) to be due to the presence of heterogeneities of different kinds, such as cleats in larger sized specimens. The general trends observed in granulated marble specimens (Figure 2) in terms of the rapid strength increase with increasing confinement can also be found for larger coal specimens, especially the $300 \mathrm{~mm}$ diameter specimens.

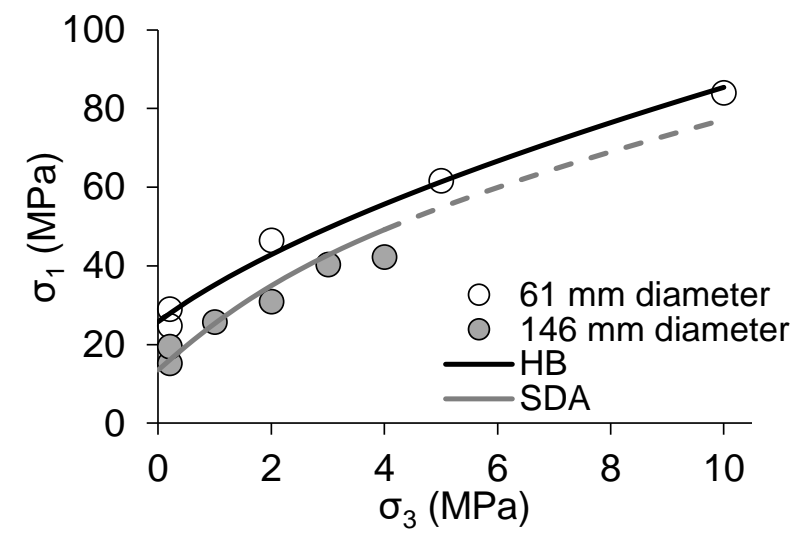

(a)

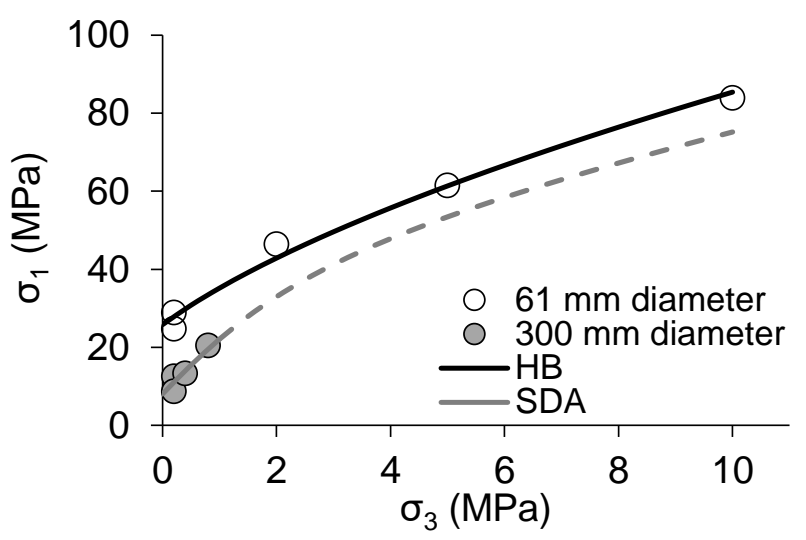

(b)

Figure 10 Laboratory data on large-scale coal specimens and the estimation of confined strength for (a) $146 \mathrm{~mm}$ diameter; and, (b) $300 \mathrm{~mm}$ diameter specimens using the SDA (Medhurst \& Brown 1998)

In the SDA analysis in Figure 10, the $61 \mathrm{~mm}$ diameter specimen is considered an intact specimen, and the 146 and $300 \mathrm{~mm}$ diameter specimens are considered to be defected specimens. Since no UCS data was available, the lower strength values of the 146 and $300 \mathrm{~mm}$ diameter specimens at $0.2 \mathrm{MPa}$ confinement were used as UCS . The unconfined and confined strengths of the $61 \mathrm{~mm}$ diameter specimens along with the estimated UCS $_{d}$ values of the 146 and $300 \mathrm{~mm}$ diameter specimens were considered to be known values. It follows from this figure that the confined strengths of both the 146 and $300 \mathrm{~mm}$ diameter specimens are reasonably estimated using the SDA for the range of confinement under which these tests were conducted.

\subsection{Method 2: Explicit numerical modelling approach}

When determining the RBS using laboratory tests, the specimens should be large enough to avoid failure along critically oriented defects, and to prevent daylighting defects from dominating the failure process. Therefore, the rock strength determined from laboratory tests on small-scale specimens cannot be used to estimate the RBS. The rock block representative element volume (REV) and its strength can be defined by 
conducting laboratory-scale effect tests. However, such tests are rarely conducted as they are expensive and time consuming. Moreover, most facilities cannot test large-scale hard brittle rocks. Here, properly calibrated numerical modelling is used as an alternative to determine the rock block REV and estimate its strength.

An integrated laboratory testing, field mapping, numerical modelling approach for the estimation of confined strength of rock blocks is proposed. The estimation of RBS using this approach requires detailed information on the strength and deformation properties of the intact rock as well as those containing the defects. The following steps are taken to estimate the confined strength of defected rock blocks:

Step 1: Conduct laboratory uniaxial and triaxial tests on intact rock specimens devoid of defects to obtain intact rock unconfined and confined strengths, and separately conduct direct shear tests on defects to obtain the shear strength properties of the defects.

Step 2: Simulate uniaxial, triaxial and direct shear laboratory tests using a distinct element model and calibrate the model to the test results. A GBM in PFC, as described in this paper, is a suitable modelling approach. However, a conventional ball model with the use of the recently developed flat-jointed contact (Potyondy 2012) could also be used as an alternative modelling method instead of the GBM method. Other alternatives are grain-based and bonded block models in UDEC and 3DEC, respectively.

Step 3: Obtain geometrical characteristics and statistical distributions of rock block defects from field mapping such as spacing, relative orientation, and continuity, and generate representative DFN models.

Step 4: Integrate DFN and distinct element models to generate synthetic rock block (SRB) models (e.g. GB-DFN model).

Step 5: Simulate scale effect tests on the SRB models and evaluate the influence of specimen size on the unconfined compressive strength of defected rocks to obtain the rock block REV.

Step 6: Simulate triaxial tests on the SRB models at their REV to estimate the confined strengths of rock blocks.

Figure 11 presents the results of uniaxial and triaxial tests simulated on models of intact (GBM) and defected (GB-DFN) specimens. Assuming that the defect properties and geometrical characteristics were obtained from field mapping (following the procedure described above), the GB-DFN models were used to estimate the strength of defected rocks and assess their strength degradation from intact rock with increasing confinement.

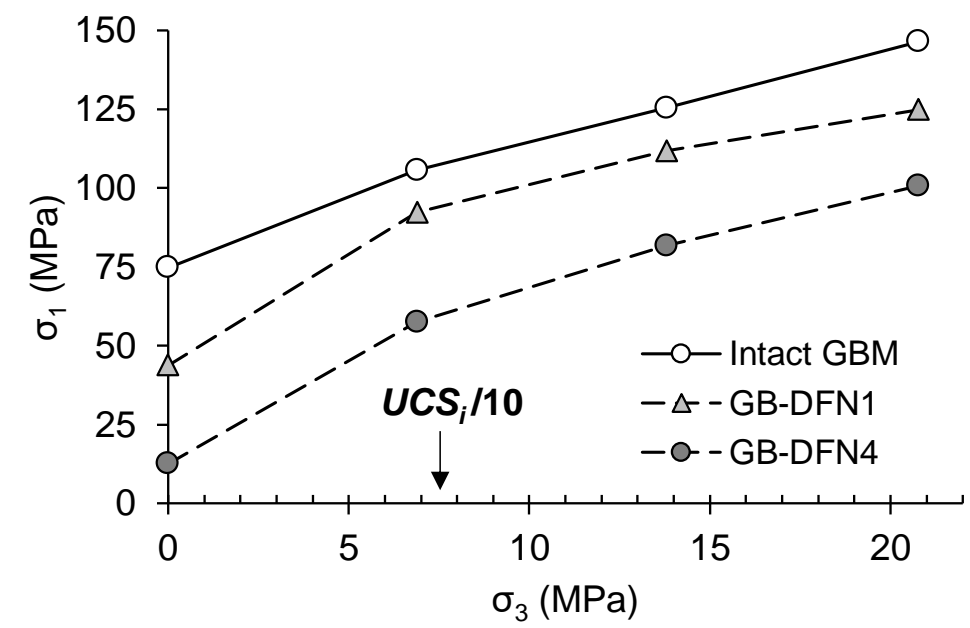

GB-DFN1

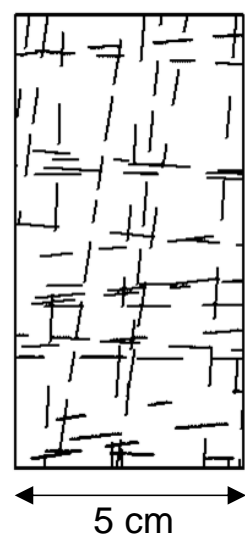

GB-DFN4

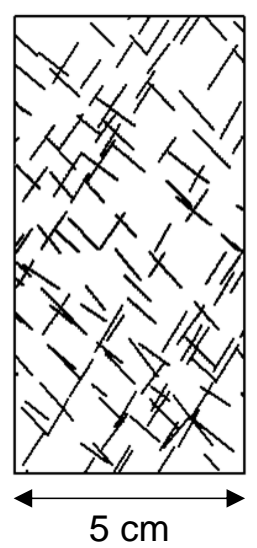

Figure 11 Unconfined and confined strengths of models of intact GBM and GB-DFN1 and GB-DFN4 (see Figure 12 for failure modes) 
Confined test simulations were conducted on $5 \times 12.5 \mathrm{~cm}$ GB-DFN1 and GB-DFN4 specimens at confining pressures of $6.9,13.8$, and $21 \mathrm{MPa}$ (Figure 11). At low confinement $\left(\sigma_{3}<U C S_{i} / 10\right)$, both defected rock models display an increase in strength with confinement at a slightly higher rate than that of the intact rock model. Beyond this critical confinement, the increase in their strengths seems to be linear, approaching about 85 and $70 \%$ of the strength of the intact rock model at the confining pressure of $21 \mathrm{MPa}$ for GB-DFN1 and GB-DFN4, respectively.

The failure modes of GB-DFN1 and GB-DFN4 at zero and $21 \mathrm{MPa}$ confining pressures are presented in Figure 12. The two sets of defects in GB-DFN1 have mean dip angles of 0 and $90^{\circ}$, whereas in GB-DFN4, two sets of defects are nearly parallel to the direction of critical shear stress. At zero confinement, GB-DFN1 involves two main types of failure - shear failure of discrete defects that are nearly parallel to the loading direction, and tensile failure of the grain boundaries between these discrete defects (rock bridges). The interaction between these two types of failure results in the formation of nearly axial macroscopic fractures. At high confinement (21 MPa), however, two major shear zones consisting of several intra-grain shear and inter-grain tensile cracks are developed independent of the orientations of defects. The failure mode of GB-DFN4 at zero confinement is fundamentally different from that of GB-DFN1, in that shear failure of critically oriented defects dominates, although some tensile crack propagation from the tips of some of the defects is observed. At $21 \mathrm{MPa}$ confinement, the failure of GB-DFN4 involves shearing of critically oriented defects, as well as failure of rock bridges consisting of several inter-grain shear and intra-grain tensile cracks.

\section{GB-DFN1}

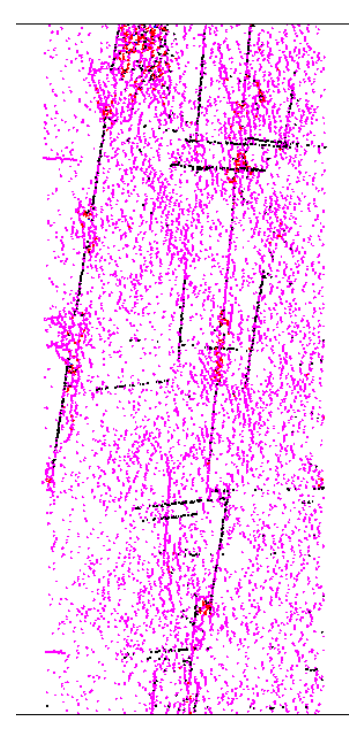

$\sigma_{3}=0 \mathrm{MPa}$

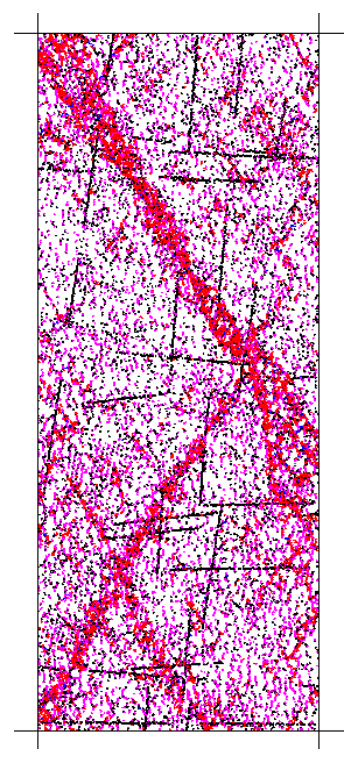

$\sigma_{3}=21 \mathrm{MPa}$

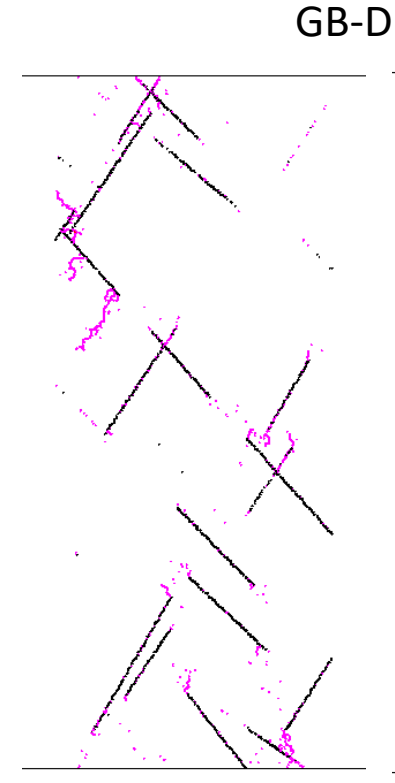

$\sigma_{3}=0 \mathrm{MPa}$
GB-DFN4

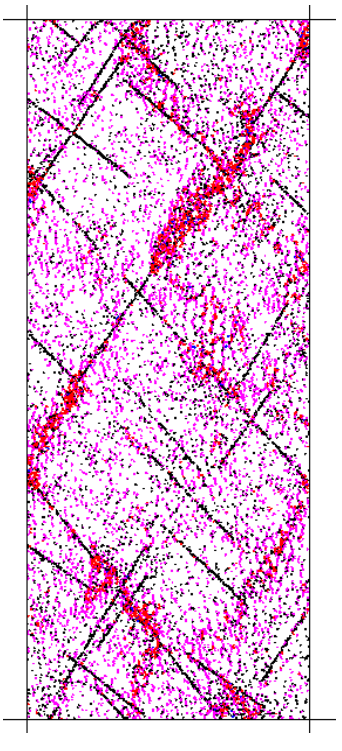

$\sigma_{3}=21 \mathrm{MPa}$

Figure 12 Failure modes of $5 \times 12.5 \mathrm{~cm} \mathrm{~GB}-\mathrm{DFN} 1$ and GB-DFN4 specimens at 0 and $21 \mathrm{MPa}$ confining pressures. Pink and black are smooth-joint tensile and shear cracks (inter-grain cracks or defects), respectively, and red and blue are parallel bond tensile and shear cracks (intra-grain cracks)

\section{Discussion}

At low confinement, the degradation of block strength due to the presence of heterogeneities as a component of the overall jointed RMS is probably negligible for practical purposes, if sufficient bridges and intact rock are present to maintain stability of the rock blocks. However, for mine pillars at great depths, where wide pillars are required that rely on the confined strength of the intact rock blocks, the degraded strength can become a significant factor. Factors such as density, orientation, strength, and persistence of the defects can affect the confined strength. 
The variability in the examples presented previously show that the proposed methods are robust for a range of conditions. If the unconfined compressive strength of the heterogeneous rock can be captured (or back-analysed), the proposed methods were demonstrated to be able to capture the effect of defects on the confined strength. In practice, it may be difficult to obtain the unconfined strength of the heterogeneous rock, as, in many cases, the defect persistence is greater than the core specimen size, or heterogeneities impart anisotropic characteristics.

The numerical simulations carried out in this study were two-dimensional, given the computational demands involved. For most rock blocks containing a system of defects, it is likely that the presence of defects in three-dimensional space also affect and thus modify the strength of heterogeneous rock blocks. Some further study on this issue is warranted.

Both methods of estimating the confined strength of defected rocks introduced in this paper require suitable laboratory and field data. In practice, obtaining specimens of heterogeneous rock that suitably capture the effects of defects in a rock block is challenging (e.g. a specimen suitable for lab testing on the order of the REV). Some judgement, in particular for anisotropic and non-uniform spatially distributed defects, is required. However, the SDA offers the advantage that it can be used without additional sophisticated and time-consuming numerical modelling. In the lack of laboratory unconfined compressive strength data for defected rocks and rock blocks, the MRMR approach can be used to estimate UCS $_{d}$ in the SDA.

The next step after estimating the confined strength of defected rock blocks is to estimate the confined strength of jointed rock masses (Figure $1(b)$ ). Once the strength envelope of the jointed rock mass is known, it can be implemented in continuum numerical codes to assess the stability of mine pillars. It has been suggested by Bahrani et al. (2014) that the confined strength of highly interlocked, non-persistently jointed rock masses is underestimated by the inappropriate use of empirical approaches, which were primarily developed for poorly interlocked, persistently jointed rock masses such as the GSI characterisation system. This has a direct implication for the strength estimation and design of hard rock pillars in deep mines; a strength envelope that properly captures the strength increase with confinement will lead to an optimised design of pillars. It is suggested that the design of wide pillars, based on common empirical approaches that tend to underestimate the confined RMS, may be adversely conservative and thus not optimal from an economic perspective. This aspect is of interest for block cave mines where drawpoint spacing may have a significant impact on cave propagation and economics. Therefore, it is necessary to develop the means to obtain a failure envelope that better captures the rapid strengthening effect due to confinement. For this purpose, future research will focus on extending the SDA to estimate the confined strength of such rock masses.

\section{Summary}

Two approaches were presented to estimate the confined strength of defected rocks (those containing specimen-scale heterogeneities). The first approach is based on the semi-empirical SDA, which was originally developed for the estimation of confined strength of crack-damaged rocks (those containing grain-scale heterogeneities). For this approach, it is necessary to establish the unconfined and confined strengths of the intact rock devoid of defects, and the unconfined strength of the defected rock. The analyses were verified in published laboratory test data on mechanically slotted marble specimens (an analogue for a laboratory specimen-scale defected rock), and large-scale coal specimens (an analogue for a defected rock block). It was found that the SDA provides a reasonable estimate for the mean confined strengths of defected specimens for the range of confinement under which the tests were conducted. The second approach, called the explicit numerical modelling approach, is based on previously calibrated GBM of Wombeyan marble, which was integrated with DFN models to generate defected rock models of various defect orientations. Triaxial tests simulated on the defected rock models indicated that the defect orientation has a major influence on the confinement-dependent strength degradation of defected rocks. 
It is suggested that the first approach (SDA) should be used at the early stages of geotechnical projects in the absence of detailed information on the defects. The explicit numerical modelling approach, however, requires detailed information on the mechanical properties and geometrical characteristics of defects, which can be obtained through laboratory testing and field mapping. Such information is used to calibrate the laboratory specimen-scale defected rock models, which are then extended to the rock block REV to estimate the unconfined and confined strengths of defected rock blocks.

This paper presented the results of ongoing research on the strength estimation of highly interlocked, non-persistently jointed rock masses consisting of hard, brittle, defected rock blocks. The estimation of the confined strength of such rock masses from the confined strength of defected rock blocks based on the proposed approaches and the stability of hard rock pillars under mining-induced loading conditions will be the focus of future research.

\section{Acknowledgement}

This research was supported by the Natural Sciences and Engineering Research Council of Canada (NSERC), Laurentian University and the Centre for Excellence in Mining Innovation (CEMI) through the Ontario government funded Smart Underground Monitoring and Integrated Technologies (SUMIT) program, the Rio Tinto Centre for Underground Mine Construction (RTC-UMC), Itasca Consulting Group through its Itasca Education Partnership program, and MIRARCO at Laurentian University.

\section{References}

Bahrani, N \& Kaiser, PK, 2013, 'Strength degradation of non-persistently jointed rock mass', International Journal of Rock Mechanics and Mining Science, vol. 62, pp. 28-33.

Bahrani, N \& Kaiser, PK 2016a, 'Strength degradation approach (SDA) for estimation of confined strength of micro-defected rocks', Proceedings of the 50th US Rock Mechanics/Geomechanics Symposium, American Rock Mechanics Association, Alexandria.

Bahrani, N \& Kaiser, PK 2016b, 'Integrated grain-based-DFN model for simulation of defected rock', in P Gomez, C Detournay, R Hart \& M Nelson (eds), Proceedings of the 4th Itasca Symposium on Applied Numerical Modeling, Itasca International Inc., Minneapolis, pp. 303-314.

Bahrani, N \& Kaiser, PK 2016c, 'Numerical Investigation of the influence of specimen size on the unconfined strength of defected rocks', Computers and Geotechnics, vol. 77, pp. 56-67.

Bahrani, N \& Kaiser, PK 2017, 'Estimation of confined peak strength of crack-damaged rocks', Rock Mechanics and Rock Engineering, vol. 50, no. 2, pp. 309-326.

Bahrani, N, Kaiser, PK \& Valley, B 2014, 'Distinct element method simulation of an analogue for a highly interlocked, non-persistently jointed rock mass', International Journal of Rock Mechanics and Mining Sciences, vol. 71, pp. 117-130.

Gerogiannopoulos, NG 1976, A Critical State Approach to Rock Mechanics, PhD thesis, University of London, London.

Jaeger, JC \& Cook, NGW 1976, Fundamentals of Rock Mechanics, Chapman and Hall, London.

Kaiser, PK \& Kim, B 2015, 'Characterization of strength of intact brittle rock considering confinement-dependent failure processes', Rock Mechanics and Rock Engineering, vol. 48, no. 1, pp. 107-119.

Laubscher, DH \& Jakubec, J 2000, 'The MRMR rock mass classification for jointed rock masses', Underground Mining Methods: Engineering Fundamentals and International Case Studies, Society for Mining, Metallurgy \& Exploration, Englewood, pp. 475-481.

Laubscher, DH 1975, 'Class distinction in rock masses', Coal, Gold, Base minerals South Africa, vol. 23.

Laubscher, DH 1990, 'A geomechanics classification system for the rating on rock mass in mine design', Journal of the Southern African Institute of Mining and Metallurgy, vol. 90, no. 10, pp. 257-273.

Martin, CD 1993, The Strength of Massive Lac du Bonnet Granite Around Underground Openings, PhD thesis, University of Manitoba, Winnipeg.

Medhurst, TP \& Brown, ET 1998, 'A study of the mechanical behaviour of coal for pillar design', International Journal of Rock Mechanics and Mining Science, vol. 35, no. 8, pp. 1087-1105.

Potyondy, DO 2010, 'A grain-based model for rock: approaching the true microstructure', Proceedings of Bergmekanikk i Norden 2010: Rock Mechanics in the Nordic Countries, Norsk Bergmekanikkgruppe - Tekna, Kongsberg.

Potyondy, DO 2012, 'A flat-jointed bonded-particle material for hard rock', Proceedings of the 46th US Rock Mechanics Symposium, American Rock Mechanics Association, Alexandria, paper ARMA12-501.

Rosengren, KJ \& Jaeger, JC 1968, 'The mechanical properties of a low-porosity interlocked aggregate', Geotechnique, vol. 18, no. 3, pp. 317-326.

Yang, SQ, Jiang, YZ, Xu, WY \& Chen, XQ 2008, 'Experimental investigation on strength and failure behaviour of pre-cracked marble under conventional triaxial compression', International Journal of Solids and Structures, vol. 45, no. 17, pp. 4796-4819. 

(defected) rocks 